\title{
NOTAS SOBRE A MEMÓRIA COMO FONTE PARA ENTENDER A HISTÓRIA DA EDUCAÇÃO
}

João Carlos da Silva ${ }^{1}$

\begin{abstract}
Resumo
Este artigo aborda a memória em seu aspecto social como lócus para entender a história da educação, abrindo possibilidades de diálogos na análise do passado, prenhe dos acontecimentos humanos, face às tendências contemporâneas do debate historiográfico. Grupos de pesquisadores em diferentes regiões do Brasil, vinculados aos Programas de Pós-graduação têm-se dedicado nos estudos sobre a memória, buscando diálogos com a história da educação. Os arquivos constituem-se espaços essenciais para construção da memória individual e coletiva, evidenciando a memória de diferentes sujeitos. $\mathrm{O}$ estudo do passado prescinde das fontes, mediante sua localização, preservação e catalogação, necessárias para preservação da memória. O objeto em tela pontua as memórias existentes e os elementos que as constituem a partir Le Goff (1990), Halbwachs (2003), Ricoeur (2007) e Lombardi (2004). Os arquivos e as fontes permitem encontrar e reconhecer o processo de construção coletiva sobre a História da Educação. A qualidade do conhecimento histórico depende da relação do pesquisador com as fontes e do entrelaçamento dos aspectos teóricos envolvidos. O ofício do historiador da educação consiste em fazer suas fontes falarem dos homens e sobre da sociedade que as produziu. O confronto entre história e memória e história da educação revela um potencial de novas possibilidades de pesquisas a ser explorado.
\end{abstract}

Palavras chave: História da educação. Fonte. Memória.

\section{MEMORY NOTES AS SOURCE TO UNDERSTAND THE HISTORY OF EDUCATION}

\begin{abstract}
This article discusses memory in its social aspect as a locus to understand the history of education, opening dialogue possibilities to analyze the past, full of human events, before the contemporary trends of the historiographical debate. Research groups in different regions of Brazil, linked to Postgraduate programs, have been devoted to studies on memory, seeking dialogues with the history of education. Files constitute essential spaces for the construction of individual and collective memory, highlighting different subjects' memory. The study of past demands sources related to their location, preservation and cataloging, necessary to memory preservation. This object focuses memories and elements that are part of them grounded at Le Goff's (1990), Halbwachs's (2003), Ricoeur's (2007) and Lombardi's studies (2004). Files and sources enable the finding and recognition of the process of collective construction of the History of Education. The quality of historical knowledge depends on the researcher's relationship with the sources and the theoretical aspects. The profession of the education historian demands its sources to speak about men and society that produced them. The confrontation between history and memory and the history of education reveals a potential of new research possibilities to be explored.
\end{abstract}

Keywords: History of education. Source. Memory.

\section{Introdução}

É possível compreender a história da educação a partir sua relação com a memória? Esta questão lança desafios aos profissionais da área. A memória vem se colocando como um foco importante nos estudos contemporâneos, cujo tema encontra-se imbricado em diferentes concepções

\footnotetext{
${ }^{1}$ Doutor em Educação pela Universidade Estadual de Campinas, professor do Colegia do de Pedagogia e do Mestrado em educação da Universidade Estadual do Oeste do Paraná (UNIOESTE), Campus de Cascavel. Pós-doutorando em educação pela Universidade Estadual do Sudoeste da Bahia UESB - Vitoria da Conquista. E-mail: joão.silva@unioeste.br
} 
em torno da relação indivíduo e sociedade, perpassando pelos desafios epistemológicos e historiográficos.

Ainda é muito recente a memória como objeto da história da educação. Vivemos na contemporaneidade cuja ideia força é regida pelo presente, do agora. Os nexos entre o presente e o passado são destruídos, como se não houvesse lugar para a memória. Mnemosine a divindade grega vivificadora, guardiã da memória, considerada uma das deusas mais poderosas e conhecidas da época frente aos perigos do esquecimento é lembrada a nos diferenciar dos outros seres vivos, isto é, valorizar a memória.

Nos últimos anos, o desenvolvimento da cibernética e da biologia trouxeram importantes contribuições em relação à noção de memória humana. A neurociência vem desvendando os labirintos da memória. $\mathrm{O}$ estudo da memória abarca a psicologia, a neurofisiologia, ate mesmo a psiquiatria quanto às perturbações da memória. Dado seu caráter polissêmico, a memória tem um papel considerável no mundo social, sendo um dos elementos constitutivos da operação historiografia. O desenvolvimento da memória artificial e eletrônica, no século XXI, abarca uma inovação neste campo ${ }^{2}$. Um conjunto de autores discorre sobre o tema, fazendo da memória objeto de suas reflexões, como em Ricoeur (2007), Benjamin (1996), Halwbachs (2003), Le Goff (1990), Bosi (2004) e Lombardi (2004).

Pierre Nora (1981) estaria certo, ao sentenciar que a massificação e a midiatização produziram a mutilação da memória? Falamos tanto da memória, porque ela já não existe mais? Estaríamos reivindicando uma memória que nos foi roubada? Estaríamos falando então de uma alienação da memória? Uma discussão sobre a memória coloca em jogo estas interrogações. A rigor as fontes também são produções humanas, merecendo um estudo a partir de suas premissas teóricas. Le Goff (1994) indica que ao tratar do homem tudo pode ser abordado em uma perspectiva histórica, inclusive a memória.

A literatura, especialmente no romantismo, em verso e prosa, valorizou a força da memória, com imbricações entre a vida privada e pública de seus personagens. O Ateneu, de Raul Pompéia, obra escrita em 1888, em que seu narrador, Sérgio, apresenta suas memórias de infância e adolescência num colégio interno. Em Itinerário de Pasárgada (1954) de Manuel Bandeira e $O$ tempo e o vento, de Erico Veríssimo 1949 também revelam recordações pessoais. Em Memórias

\footnotetext{
${ }^{2}$ Do ponto de vista da neurociência, a memória é uma das funções do sistema nervoso, resultado da comunicação entre as células, permitindo a ligação de receptores na membrana da célula, que estimulada, produz o desencadeamento de um conjunto reações químicas. Nossa história em vida é nutrida por experiências, desde a infância que não esquecemos, deixando marcas definitivas como uma visita às Cataratas do Iguaçu ou ao litoral brasileiro. Nesta esteira, vivemos tempos de obsessão pelos documentos, pelos arquivos e monumentos. Produzir arquivo tem sido o imperativo na contemporaneidade. Não existe uma história-memória, mas uma memória que foi solopada pela história, isto é, oculta pelos acontecimentos.
} 
póstumas de Brás Cubas, (1881), de Machado de Assis, Memórias de um sargento de milícias, de Manuel Antônio de Almeida, (1852) e Memórias do cárcere, (1953) de Graciliano Ramos, ilustram este panorama.

Grupos de pesquisadores em diferentes regiões do Brasil, vinculados aos Programas de Pósgraduação têm se dedicado nos estudos e pesquisas sobre a relação da memória, buscando diálogos com a história da educação. Neste empreendimento podemos destacar o Programa de Pósgraduação de Memória: Linguagem e Sociedade, na UESB - Universidade Estadual do Sudoeste da Bahia - Vitória da Conquista. Vinculado ao Museu Pedagógico tem oferecido importantes contribuições, como campo de investigação e problematização, privilegiando a perspectiva epistemológica e a análise crítica.

Destaca-se ainda o grupo de pesquisa Memória, História e Educação - Faculdade de Educação/Unicamp, como às investigações voltadas para a história da educação no Brasil. Temos ainda o Centro de Pesquisa Integrada de História e Memória da Educação (CEPIHME), Manaus. Mestrado de História da Universidade Federal do Piauí, com pesquisas que discutem as relações entre memória e a produção histórica dos lugares, indagando sobre como as categorias cidade, memória e história se relacionam o que permite refletir, no caso da História do Brasil.

O Grupo de Estudos e Pesquisas "História da Educação da Paraíba" - HISTEDBR/GT - PB. Mestrado em Educação Universidade Estadual de Ponta Grossa - UEPG, O Grupo de Pesquisa CRONOS - História Ensinada, Memória e Saberes Escolares - constituído no interior do Programa de Pós-Graduação em Educação da Universidade Federal de Juiz de Fora, dedica-se a investigar as relações possíveis entre as práticas sociais Memória e suas relações com a aquisição do pensamento histórico nos diferentes processos educativos, além do Grupo de Pesquisa História e Memória da Educação - Grupehme UNESC, Santa Catarina. Neste conjunto vale pontuar "Cadernos do CEOM", publicação do Centro de Memória do Oeste de Santa Catarina, tendo como objetivo publicar resenhas e artigos inéditos no Brasil relacionados à História, Arqueologia, Antropologia, Sociologia, Museologia, Arquivística e Educação, vinculado ao UNICHAPECÓ.

Entendemos que a produção historiográfica em tela não emerge descolada do conjunto da produção educacional brasileira, mas se dá no interior dos trabalhos que têm por objetivo analisar a pesquisa educacional no Brasil, inclusive a produção histórico-educacional. O contexto das transformações do final do século XX, caracterizado pelo fim do bloco socialista e crise mundial do capitalismo, profundas mudanças no processo de produção baseadas na informática, na robótica, na microeletrônica, na biogenética e na biotecnologia trouxeram novos elementos no fazer da operação historiográfica. 
A partir principalmente da contribuição da nova história brota o conceito ampliado de fontes documentais. Por sua vez, despertará essa corrente, de modo muito específico na História da Educação, um grande interesse em coletar, organizar, sistematizar documentos escritos, inscritos, orais entre outros, que constituem a memória da educação nacional, regional, local em suas redes pública e privada.

E hoje, se há certa unanimidade na contribuição da nova história quanto à ampliação do conceito de fontes documentais, também não há dúvida, que a apreensão pelo campo da história da educação com relação a correntes teóricas marxistas, continua bastante demarcadas, o que não significa que não haja o diálogo, a mediação de suas abordagens com a da nova história. De modo sintético, diríamos que do ponto de vista marxista, há uma predominância dos estudos das condições materiais e a luta de classe que presidem a realidade histórica educacional na relação parte com o todo. Já na chamada história dos analles ou história nova não expressa todas as suas variantes, se centra mais no chamado "mundo da cultura" e sua autonomia dentro da totalidade.

Explicar o passado, prenhe dos acontecimentos humanos, em função do presente, talvez seja a principal função social do pesquisador. Mediante suas fontes, o desafio do historiador consiste a rigor dar significado as atitudes, valores, intenções e convenções que fazem parte das ações

humanas. É na contracorrente desta tendência de desvalorização da memória que formulamos este artigo. Seguindo as pegadas de Ricouer, podemos dizer que a busca pelo acontecimento histórico, pressupõe a luta contra o esquecimento.

A rigor o discurso sobre a memória é tão antigo quanto à historiografia ocidental, cuja elaboração remonta aos gregos, nas filosofias platônica e aristotélica. O primeiro bordando o tema pelo viés da imaginação e o segundo pela ideia de lembrança. Neste artigo apresentamos alguns apontamentos acerca da relação entre História-Memória como locus de reconstrução da história da educação no sentido de contribuir com o debate acerca da temática.

\section{A história-memória}

O trabalho do historiador vem se aperfeiçoando, assim como a relação entre pesquisador e documento. Inicialmente na historiografia, apenas os documentos oficiais e escritos eram considerados fontes historiográficas, vistos como sinônimos de verdade incontestáveis, cabendo ao historiador descrevê-los.

As grandes transformações no campo historiográfico remetem especialmente ao século XIX, onde havia uma preocupação em transformar a história em uma ciência com método específico. 
Grande parte dessas mudanças, foi influenciada pelo iluminismo, apresentando profundas transformações de pensamento sobre a história.

Em se tratando de história, a operação historiográfica nunca é uma atividade simples dado seus aspectos dinâmicos em constantes transformações. Schaf então indaga: porque reescrevemos continuamente a história? O mesmo autor responde: deve-se em função das necessidades atuais que a sociedade impõe e dos efeitos dos acontecimentos do passado no tempo presente. Nesta linha de raciocínio, os insatisfeitos e a instabilidade do presente levam-nos a instigar e reinterpretar o passado na perspectiva dos acontecimentos do presente.

Nesse contexto, são lançadas as bases para um novo modo de pensar a história, alguns historiadores vêem a necessidade da criação de normas e regras específicas para então denominada “ciência da história”. Nesse sentido Schaff aponta:

É, portanto, falso acreditar, como o faziam os positivistas, que os fatos históricos, porque são historicamente importantes, significativos, se destacam por si mesmos dos outros acontecimentos ou processos históricos, e que o historiador se deve limitar a registrá-los e a apresentá-los, uma vez que o seu significado é suficientemente "eloquente" (SCHAFF, 1995, p. 234).

As fontes constituem a principal ferramenta do trabalho do pesquisador, são elas que viabilizam, ou não, um trabalho científico que proporcionará a construção de uma pesquisa. São elementos fundamentais para produção do conhecimento histórico. Neste sentido, o trabalho de busca, levantamento e identificação das fontes, são essenciais para constituição da memória histórica ${ }^{3}$.

O alargamento do termo documento foi uma etapa importante da revolução documental que se produziu a partir dos anos de 1960. Se até então o princípio era o documento, agora o princípio torna-se o problema, diante do acervo a sua frente. Novos arquivos são instituídos e a memória coletiva valorizada, tornando-a verdadeiro patrimônio cultural.

Vivemos tempos interessantes marcados pela passagem do testemunho oral para o testemunho escrito, ou como alguns preferem fase da revolução documental. A rigor, o momento do arquivo, ao ganhar notoriedade, é o instante denominado por Michel de Certeau, operação historiográfica, momento da escrita, cujo historiador profissional, na luta com o documento, garantido pela lei de acesso, sai em busca de socorro.

\footnotetext{
${ }^{3} \mathrm{O}$ campo da historiografia educacional brasileira tem tido um impulso significativo nas últimas décadas com pesquisas abordando vários temas. Esta diversidade encontra apoio teórico na "Nova História Cultural" produzida na França como alternativa à história "historicizante", positivista, que prioriza a história política e o culto aos heróis. A "Escola dos Annales" trouxe significativas na produção historiográfica, influenciando os pesquisadores na investigação de novas temáticas.
} 
Para além de um lugar físico, o arquivo é um espaço social, onde a história está posta, onde se reuni, separa e coleta, em busca do rastro do passado ${ }^{4}$. É sabido que os documentos somente falam se lhes pedem que confirmem. A rigor, a pergunta constrói o objeto de pesquisa. Nas palavras de Ricoeur: "Rastro, documento e pergunta: são os tripés do conhecimento histórico" (2007, p. 188).

O documento se torna enquanto tal, somente quando procurado, encontrado, construído, instituído, questionado por um feixe de perguntas e rastreado no estudo e na análise. Documento, pois, é tudo aquilo que pode ser questionado com a finalidade de encontrar algumas informações sobre o passado, a partir de um olhar sempre desconfiado acerca de certas afirmações cristalizadas, onde o verdadeiro ou o falso são colocados a prova.

A memória é a mais épica de todas as faculdades, fonte de história e conhecimento e não meras reminiscências daquilo que nos causou dor, prazer e sofrimento. Mas a arte de narrar está em vias de extinção, dizia Benjamin. São cada vez mais raras as pessoas que dominam esta arte, sentencia o filósofo alemão.

A palavra história remonta a Antiguidade. Quando conhecida, foi reduzida a um lugar secundário, como se estivesse atrapalhando interesses hegemônicos em jogo. Aos olhares dos comtianos e sociólogos era disciplina com pouca importância, sem credito, no máximo estudavamse os fatos humanos, sem nenhum nexo com o passado ou suas origens. Procurando ser preciso nas palavras e no vocabulário, Bloch afirma que a história não é a ciência que estuda o passado, mas é a ciência das sociedades humanas. A rigor, história é a ciências das sociedades humanas no tempo, marcado por um passado diverso, cheio de nuances, cujo objeto é os homens, é para eles que a história deve mirar ${ }^{5}$.

Le Goff (1994), nos alerta que documento não é qualquer coisa que fica por conta do passado, mas é produzido pelas forças que detêm o poder na sociedade. Os elementos que propiciam a produção a respeito da história-memória podem contribuir significativamente com uma pesquisa, quando os mesmos são utilizados como meio de explicação de um fenômeno para além de sua aparência, sendo interrogados e argumentados no presente, articulados ao momento em que foram produzidos.

Neste prisma, nos últimos anos a pesquisa histórica conheceu um avanço importante na renovação, mediante o enriquecimento das técnicas, dos métodos e dos horizontes da operação

\footnotetext{
${ }^{4}$ Nesta linha estaríamos vivenciando uma aproximação, entre a sociologia e a história, mas uma luta de aproximação. Ao que parece essas duas áreas parecem buscar respostas comuns de observação e de critica sobre aos acontecimentos. ${ }^{5}$ Febre e Bloch fundadores, em 1929, da revista Annales d'Histoire Economique et Sociale com o objetivo de problematizar a história em diversos campos social, passava a enfatizar temas presentes no cotidiano, dentre eles o amor, a morte, a família, a criança, as bruxas, os loucos, a mulher, os homossexuais, etc., causando um importante impacto nos objetos de investigação histórica.
} 
historiográfica e dos domínios da escrita ${ }^{6}$. Por outro lado, o aumento do saber sobre a história na contemporaneidade trouxe também seu contraditório, isto é, uma crise marcada por novos desafios, caracterizada pela expansão da historiografia. Fala-se hoje de uma história visual ou história virtual.

Sem dúvidas que nas últimas décadas temos assistido um enriquecimento da escrita da história, permeadas por práticas interdisciplinares, novos interesses de estudos e novos objetos. Novos documentos são armazenados, exigindo a organização de bancos de dados e com ele uma nova erudição acerca da pesquisa historiográfica. Le Goff, nos alerta que não devemos nos contentar com esta revolução documental, mas devemos avançar á uma crítica radical sobre a documentação levantada e catalogada ${ }^{7}$.

O termo memória coletiva, originalmente cunhado pelo sociólogo francês Maurice Halbwachs, assim é definido por Le Goff (2003, p. 95):

Memória coletiva é o processo social de reconstrução do passado vivido e experimentado por um determinado grupo, comunidade ou sociedade. Este passado vivido é distinto da história, a qual se refere mais a fatos e eventos registrados, como dados e feitos, independentemente destes terem sido sentidos e experimentados por alguém.

Halbwachs perpassando pelas classes sociais e atingindo aos estudos dos quadros sociais, considera que a memória nunca é só individual, pois nunca estamos sós. Em ultima instância, vivemos imersos em um coletivo, marcado por uma trama de relações onde a família é parte fracional, estabelecendo relações e convivências, partilhando e compartilhando experiências, isto é, toda lembrança individual está ligada as recordações de um grupo. Em outros termos, para lembrar é preciso do outro. Grosso modo, lembraremos se nos colocarmos no ponto de vista de um grupo ou de uma corrente de pensamento. Outro sim, o mesmo autor sentencia que a lembrança consiste em uma reconstrução dos acontecimentos do passado com auxílio de dados tomados do presente (HALBWACHS, 2003).

A sociedade está composta por uma teia de grupos segmentados, uma rede de comunicação e de correntes de pensamentos diversos, que se interconectam. Muitas vezes parece rechaçar a ideia de história, ao afirmar que ela parece um cemitério. Entende o processo histórico não como uma sucessão de acontecimentos, mas algo que distingui um período do outro. Não vê com bons olhos o termo memória histórica. Sobre os nexos entre história e memória, Halbwachs (2003, p. 86) diz:

\footnotetext{
${ }^{6}$ Febre e Bloch fundadores, em 1929, da revista Annales d'Histoire Economique et Sociale com o objetivo de problematizar a história em diversos campos social, passava a enfatizar temas presentes no cotidiano, dentre eles o amor, a morte, a família, a criança, as bruxas, os loucos, a mulher, os homossexuais, etc., causando um importante impacto nos objetos de investigação histórica.

${ }^{7} \mathrm{~A}$ história não só deve permitir compreender o "presente pelo passado" - atitude tradicional - mas também compreender o "passado pelo presente".
} 
A história não é todo o passado, mas também não é tudo aquilo que resta do passado. Ou, se o quisermos, ao lado de uma história escrita, há uma história viva que se perpetua ou se renova através do tempo e onde é possível encontrar um grande número dessas correntes antigas que haviam desaparecido somente na aparência.

Marc Bloch (2001) em Apologia a história, ou o oficio do historiador, sai em defesa da história e do historiador como profissional, valorizando a memória como uma das matérias primas da história. Para ele, o historiador deve ser faminto, um devorador de história, dialogar com a sociologia, mas sem confundir com esta. Os estudos exploratórios e dialéticos têm revelado grande potencial criativo de pesquisa, fazendo emergir propostas inovadoras no campo da história da educação. Dessa forma, a historiografia surge como sequência de novas leituras do passado, plena de perdas e ressurreições, falhas de memória e revisões.

Estas atualizações também afetam o vocabulário do historiador, introduzindo-lhe anacronismos conceituais e verbais, que falseiam a qualidade do seu trabalho. Em primeiro lugar, porque há pelo menos duas histórias: a da memória coletiva e a dos historiadores. A primeira é essencialmente mítica. O desejável é que a informação histórica, fornecida pelos historiadores de ofício, vulgarizada pela escola (ou pelo menos deveria sê-lo) e a mass media, corrija esta história tradicional falseada. A história deve esclarecer a memória e ajudá-la a retificar os seus erros. Como nos alerta Le Goff, todo o documento é um monumento ou um texto, e nunca é "puro", isto é, puramente objetivo.

O trabalho do historiador se exerce a partir da combinação de ação individual e em equipe. Seguindo a máxima de Marc Bloch (2001), de fato os documentos somente falaram quando sabemos interrogá-los, aí estará o sucesso ou revés ao se trabalhar com a massa documental ${ }^{8}$. O annales produziu uma renovação nos estudos, ao fincar a história-problema a partir de estudo interdisciplinar. Bloch, se arrisca a responder como e por que o historiador exerce seu oficio, afirmando que deve ser uma atividade de entretenimento sem o qual não vê o para que escolher este desafio.

Antes de julgar a história, precisamos compreendê-la, em suas crenças, crises políticas, economia e na estrutura de classes. A luta contra a visão comtiana eivada de positivismo de história contínua, denominada a pré-história historiográfica, que reduzia a ciência em estudo dos fatos e não das causas.

\footnotetext{
${ }^{8}$ Estudar a história é se deslumbrar diante do espetáculo da vida humana, neste sentido todo exercício intelectual consiste em uma obra de arte. Afinal, como já dizia Bacon, no século XVII, a ciência deve ter um único objetivo: tornar a vida melhor e fazer de os homens serem felizes. Por outro lado, Fustel de Colanges, considera que a história é uma das mais difíceis das ciências, por isso que é imprescindível o historiador se profissionalizar.
} 
Para Bloch, o historiador deve ser o farejador de carne humana. Onde estiver o homem ali deve se fazer presente o historiador, em busca de sua presa, logo, uma história a ser desvelada. Quem não se propor a isso não passará de uma balbuciador, um especulador da história. A presença humana se faz em todo lugar, todo que ele cria, produz, escreve, registra, tudo que ele fabrica são testemunhos históricos. Assim é adequado no estudo dos problemas humanos manejar diversidades de vestígios e testemunhos históricos. Eis o principal desafio do historiador ${ }^{9}$.

Bloch colocando-se contrário ao modelo comtiano reivindica a abertura e acesso irrestrito aos arquivos considerados sagrados com, por exemplo, das igrejas que certamente guardam verdadeiras relíquias acerca dos acontecimentos humanos. Nesta tarefa, os annales e suas criticas a história descritiva teve um papel fundamental ao valorizar o acesso aos acervos públicos e privados a contra a privação dos historiadores aos registros, prenhe de acontecimentos humanos. Este foi um importante avanço no contexto da história da educação ao tornar a história um grande arquivo a ser explorada fonte inesgotável de possibilidades.

Nunca devemos aceitar cegamente todos os testemunhos ou vestígios históricos ${ }^{10}$. Assim como jamais devemos dar credito a qualquer noticia de jornal ou de TV. Urge ficar alerta contra os embustes, as falsificações, os plágios, a fraude, as imitações, com a manipulação dos fatos, as mentiras, classificações e periodizações aleatórias, falsos testemunhos, deformações, os impostores, pois as falsificações podem dizer a verdade e ela perdurar por séculos. A mentira em certos seres humanos torna-se um ato gratuito.

$\mathrm{Na}$ análise histórica, estaremos sujeitos a três possibilidades: o historiador como imparcialidade, como reprodução ou como tentativa de reprodução ou tentativa de análise. Mas todo historiador nunca está alheio as paixões. Talvez lhe reste apenas isso. O risco, que corremos é cada um ficar com seu pedaço sem observar a obra de arte inteira.

Nossa memória coletiva, isto é, aquilo que dá uma unidade, conservara certamente a sociedade do "eu", centrada no lucro, no consumismo. A rigor Bloch, está em embate com os antigos manuais eivados de abordagens positivistas e idealistas, com interpretações lineares, afirmações simplificadoras, acomodadas em relatos superficiais e petrificados pela história.

\footnotetext{
${ }^{9}$ Ao reivindicar a tarefa de estudar a história a um profissional, o faz dizendo que a história humana está marcada por acontecimentos muito delicados, que fogem a qualquer tentativa de improvisações. A rigor um acontecimento nunca é bem compreendido se não estudar as causas. Assim a pesquisa em história deve estudar as causas. Neste empreendimento, isto é, na operação historiográfica é recomendável que esteja presente o estudo das origens. Mas para iniciar a formulação de um problema, urge observar o panorama dos acontecimentos do momento.

${ }^{10}$ Uma ciência que constatasse tudo aquilo que já se previa é pouco proveitosa e divertida. Assim a dúvida e a probabilidade sempre devem ser instrumento para se atingir o conhecimento. A rigor a história deve a ciência que deve decompor o real. Considerada que a pobreza de inventividade assola a maioria dos homens. O desafio é criar e abrir novas possibilidades de pesquisa, por caminhos ainda não percorridos. Via de regra acusa o positivismo de eliminar a ideia de causa nos estudos históricos.
} 
Conforme Bloch (2001, p. 150) sentencia: “a história, não esqueçamos, ainda é uma ciência em obras.".

A escrita da história nasceu na Antiguidade como relato, em Heródoto e Tucídides, ou seja, a história "daquilo que vi", está aí a história testemunhada ou história-relato. Dava-se inicio a produção de documentos, escritos e a sua guarda em arquivos ou bibliotecas. Desde o século passado, assistimos ás duras criticas a este tipo de história, baseada numa visão cristã, positivista e idealista dos acontecimentos, mediante a afirmação de uma história explicativa, critica ou analítica, que busque as causas. A noção de documento também sofreu sua depuração pela reflexão histórica, como material bruto, objetivo, tão cara á história tradicional. A tomada de consciência do historiador acerca da não neutralidade do documento histórico talvez tenha sido uma das principais transformações produzidas.

A rigor, a interpretação do mundo trás em seu bojo o desejo de mudá-lo, afinal a história também é, em ultima instancia, uma prática social. Não se deve privilegiar uma realidade sobre outra, não devendo conferir exclusividade ao motor da história. Uma explicação eficaz da história deve por em confronto todas as realidades que cortam a história. Sem duvida que o ideológico, o político e o econômico devem ser colocados em confronto permanente, pois a história deve ser história social.

Diferente da historiografia tradicional, que expressava uma visão reacionária, valorizada o passado como algo decadente e superado pelo presente, o interesse pelo passado está em esclarecer o presente. A aproximação da história com outras ciências sociais como a antropologia e a arqueologia, trouxe alargamento dos objetos de estudo, métodos, problemas e questionamentos.

Concordando com Le Goff, falar de história não é tarefa das mais fáceis. Começando pelo seu sentido etimológico. A palavra história, do grego antigo, historie aquele que procura que vê, que testemunha. Assim a história tem suas origens na narração, na descrição, podendo ser verdadeira ou falsa, podendo ser uma realidade ou uma fábula, uma history ou story. O italiano atribui o conjunto desta produção como historiografia.

É preciso estar atento às denominações grosseiras e mistificadoras sobre o sentido da história. Ela sempre será uma história inexata, confusa caso contrário ela não seria uma ciência histórica, ai está sua singularidade. Nos últimos anos enriqueceu suas técnicas seu campo de domínio, passou por uma renovação, humanizou-se enquanto ciência, pois passou a falar mais da sociedade humana e menos dos heróis, ou seja, tornou-se uma história social. Paradoxalmente, sua complexidade aumenta quanto mais seu poder aumenta. Dar sentido ao passado em função do presente, eis ai a função social da história. A historiografia assim tem a função de fazer novas leituras, corrigir falhas, 
fazer revisões e atualizações, esclarecer a memória, isto é, está dizendo que a história produzida pelo autor está mal escrita, que é preciso rever o que foi feito. Vale a afirmação de Paul Valéry, ao dizer que a história é o produto mais perigoso que a química do intelecto humano já produziu ${ }^{11}$.

\section{A memória e sua relação com a história da educação}

Na década de 1980 surgiram trabalhos como: dissertações, teses que incluem a categoria gênero como fundamental para interpretação, tanto aquelas que têm por objeto a mulher e suas particulares relações, seja na família na empresa ou na escola. A história da mulher tomou forma no Brasil sob o nome de movimento feminista que tinha como objetivo fundamental a conquista de direito iguais aos dos homens as mulheres. Esse movimento repercutiu nas pesquisas e nas obras resultantes sobre tudo no campo das ciências sociais e Humanas (LOPES, 2001)

Os registros históricos são peças usadas pelos historiadores, para produzirem determinadas explicações históricas, neste viés Aróstegui diz:

[...] a história não é uma narração dos fatos memoráveis, geralmente políticos, que ilustram a vida dos grandes homens, os governantes e os poderosos, mas se refere aos fatos da civilização e que é uma explicação do passado e não sua descrição (ARÓSTEGUI, 2006, p. 102).

As transformações no conceito de fontes pela escola dos annales influenciaram o pensamento historiográfico contemporâneo, com uma diversidade de fontes, entre elas as orais, escritas ou visuais, possibilitando uma ampliação no objeto do historiador.

A História, escrita e reescrita, é influenciada pelo desejo de esclarecer e compreender as transformações do homem em sociedade, provocando, assim, no historiador, a busca pelo conhecimento do passado. Assim esse resgate acontece graças aos vestígios de fontes documentais, como é o caso de fontes impressas, visuais, áudio visuais, iconográficas, etc.

Marc Bloch (2001, p. 77) assim considerou a importância dos documentos para a memória e para a história:

[...] os documentos não aparecem, aqui ou ali, pelo efeito de um qualquer imperscrutável desígnio dos deuses. A sua presença ou a sua ausência, nos fundos dos arquivos, numa biblioteca, num terreno, dependeu de causas humanas que não escapam de forma alguma à analise, e os problemas postos por sua transmissão, longe de serem apenas exercícios de técnicos, tocam, eles próprios, no mais intimo

\footnotetext{
${ }^{11}$ A rigor, o momento do arquivo, ao ganhar notoriedade, é o instante denominado por Michel de Certeau, operação historiográfica, ou seja, momento da escrita, cujo historiador profissional, na luta com o documento é o leitor, que garantido pela lei de acesso, sai em busca de socorro. Para alem de um lugar físico, o arquivo é um espaço social, onde a história está posta, onde se reuni, separa e coleta, em busca do rastro do passado. Nesta linha estaríamos vivenciando uma aproximação, entre a sociologia e a história, mas uma luta de aproximação. Ao que parece essas duas áreas parecem buscar respostas comuns de observação e de critica sobre aos acontecimentos.
} 
da vida do passado, pois o que assim se encontra posto em jogo é nada mais nada menos do que a passagem de recordação através das gerações.

Compreendemos que o saber histórico possui sua própria historicidade, sendo a própria realidade histórica do historiador o motor impulsionador das suas indagações, por meio dos questionamentos e dos problemas atuais, que serão colocados ao passado humano.

O registro histórico é construído pelo historiador: "A história não é uma memória individual, mas uma memória coletiva. Os indivíduos obtêm dos outros o conhecimento dos fatos históricos, selecionando, é verdade, aqueles que desejam." (PENN, 2009, p. 24). A história construída não é uma memória individual, mas uma memória coletiva. Aqueles que escrevem a história selecionam a verdade que desejam que seja registrada.

O estudo do passado, por meio de fontes primárias, possibilita a compressão de valores, ideias e diferentes concepções de sociedade que integram as instituições em seu espaço e no tempo. A reconstrução da história prescinde basicamente das fontes, mediante sua localização, preservação e socialização, necessárias para preservação da memória. Nesse sentido Le Goff (1194, p. 470) destaca:

O documento não é qualquer coisa que fica por conta do passado, é um produto da sociedade que o fabricou segundo as relações de forças que aí detinham o poder. Só a análise do documento enquanto monumento permite à memória coletiva recuperá-lo e ao historiador usá-lo cientificamente, isto é, com plena causa e conhecimento.

Todo documento é um monumento, resultado de escolhas e intenções de quem o produziu, sendo criado em uma conjuntura, a qual relações sociais, políticas e interesses individuais direcionam seus objetivos. Nesse sentido história não deve consistir em uma narração dos acontecimentos, mas compreender os fatos do passado sobre diferentes perspectivas.

A nova historiografia ao combater a História tradicional, baseada em "uma perspectiva cumulativa e progressista" possibilitou a criação de novos métodos e possibilidades, para produção do conhecimento científico. Sempre estamos reescrevendo a história e este processo deve-se basicamente, em função das necessidades do presente e dos efeitos dos acontecimentos do passado no presente, afinal, a história é escrita com base em indagações e questionamentos do historiador que está em seu tempo presente olhando para o passado.

A qualidade do conhecimento histórico depende da relação dos historiadores com as fontes, a pluralidade de fontes disponíveis deve ser analisada e interpretada pelo historiador, cuja abordagem deve partir de uma metodologia especifica para cada tipo fonte, por exemplo, uma fonte oral terá 
um tratamento diferençado de um documento do judiciário, ou ainda de uma fotografia. Cabendo ao historiador optar pela metodologia mais adequada a sua pesquisa.

Quando pretendemos desenvolver uma pesquisa ou uma resposta para um problema, frequentemente vamos ao passado o mais longe o possível, a fim de tentar responder as questões do problema de pesquisa. A trajetória da maioria dos pesquisadores ao realizar o levantamento bibliográfico, é percorrer o passado longínquo e fazer resumo histórico. Sem dúvida que é importante situar esse importe dentro da pesquisa, mas não gastar exaustivas páginas ou capítulos com os mesmos.

Não é raro encontrarmos pesquisas, que vão ao passado, buscar fatos para se responder a questões do presente, o problema que se procura em fatos isolados, a resposta para questões contemporâneas. Porém, esses fatos precisam ser articulados para que se construa uma compreensão da totalidade. Grosso modo acabamos destacando uma história dos vencedores, vista como natural, sem muitas vezes observar sua totalidade e suas contradições produzidas a partir de condições materiais.

Lombardi, (2004) ao discutir significado dos termos história e história da educação, centra suas observações sobre os vários sentidos que o termo história implica, e a ambigüidade que o termo apresenta como uma moeda de diferentes faces, buscando seu entendimento a partir da análise marxista. A ciência da história pode ser examinada os sob dois aspectos: em história da natureza e história dos homens, ainda que prevaleça viés dialético, pois existe a natureza porque existem os homens e vice e versa. A história da educação só se constituiu disciplina diferenciada, na perspectiva de ampliação e aprofundamento da concepção e classificação de ciência a partir da matriz positivista e suas variantes.

O segundo conceito discutido por Lombardi é historiografia, onde apresenta três concepções: seguindo a indicação de Abbgnano, em que a historiografia se constitui a partir de dois termos: grafia e história. A primeira, podendo ser traduzido como escritas da língua portuguesa, sendo sua utilização recente cunhada pelo monge Tomaso Campanela como significado de arte de escrever corretamente. A segunda, usado por Croce o pai do presentismo em que a historiografia se tratava de um campo da própria história e dedicado ao estudo dos conhecimentos históricos (LOMBARDI, 2004).

Podemos entender que a historiografia da educação como um campo de estudo que tem por objeto de investigação as produções históricas que estudam a educação. Outro aspecto a ser discutidos é a questão das fontes históricas e fontes historiográficas. Não é possível o entendimento do objeto de investigação sem as fontes. Essas mesmas fontes nem sempre são encontradas 
facilmente, de forma semelhante ao uso da fonte de água pelo homem, na maioria das vezes se torna acessível depois de várias buscas, pois nem sempre todas as ações históricas ficaram registradas para a posterioridade, e não poderão ser recuperadas e contadas.

Ainda com relação às fontes, é preciso destacar que o historiador elege, organiza e interpreta suas fontes em conformidade com suas opções metodológicas e teóricas. Nem sempre documentos ou testemunhos, artefatos que o homem produziu tornam possível o entendimento do homem sobre sua própria trajetória, resta ao pesquisador a alternativa: definir o que deseja estudar delimitado o objeto de investigação e buscar outro tipo de fonte que ajude á novos dados, todos os tipos de fontes são válidos, pois a diversificação pode revelar aspectos e características diferenciadas das relações do homem para além das fontes convencionais. A pesquisa em história da educação tem se beneficiado pelo uso de informática e comunicação, muitos sites oferecem uma grande quantidade de fontes disponibilizadas por fidedignas instituições depositárias (LOMBARDI, 2004, p. 159).

Por sua vez, Le Goff, ao falar sobre o oficio do fazer a história, considera que a obra do historiador é uma forma de atividade simultaneamente poética, científica e filosófica. Alguns historiadores contemporâneos, entre eles Georges Duby, consideram o oficio de fazer a história como uma arte, um gênero literário. Deve conservar um discurso, não qualquer discurso, mas um bom discurso, erudito, em trabalho intelectual de muita imaginação, capaz de dar vida aquilo que aparenta estar morto nos documentos. A rigor, o passado e a memória são os objetos da história, sendo esta um nível básico de elaboração histórica.

Halbwachs (2003) sugere que lembrar é um ato individual, mas que se realiza e se completa na instancia familiar que por sua vê se estende ao coletivo. Diz o autor que a memória individual está entrelaçada ao seu meio, depende de sua relação com seu entorno familiar, com as instituições sociais. Lembramos porque alguma situação do presente ou alguém nos faz lembrar, assim está sempre ligada à esfera de um coletivo. Tanto em Halbwachs como nos estudiosos da memória, algo em comum se destaca, isto é, que a memória não deve ser compreendida de maneira isolada, circunscrita a esfera individual, mas deve ser colocada em confronto com a prática social.

O sociólogo durkheimiano considera que a memória nunca é só individual. Ademais, memória coletiva não deve ser confundida com memória histórica dizendo: "A história é a compilação dos fatos que ocuparam maior lugar na memória dos homens" (HALBWACHS, 2003, p. 100)

Benjamin (1994) considera que a sociedade industrial é danosa para a memória, levando ao declínio a arte de contar história, por instaurar uma ordem pragmática, centrada na produção, no consumo desenfreado de mercadoria, desvalorizando todo o resto, inclusive a memória. O triunfo 
da sociedade de massas, calcado na informação imediata, vendável, superficial, repetitiva e alienante, coisificou o homem.

A civilização burguesa, ao controlar os meios de produção da informação, desfez o conhecimento do passado, eivado de conflitos, afinal desvendar os acontecimentos e as formas de tomada de poder praticadas tornam-se ameaça a ordem vigente, isso não interessa. Nesta lógica, Mnemosine, deusa da recordação, é posta na clandestinidade. Na ordem burguesa, o esquecimento, mediado pela ideologia e pela alienação, é sempre necessário. O consumismo, o individualismo e a competição é que não podem ser esquecidos

\section{Considerações finais}

Dizer que não existe produção "neutra" do conhecimento histórico, assim como toda produção historiográfica não pode ser abstraída do tempo em que surgiu, significa afirmar que todo intelectual define-se em relação às lutas e aos projetos sociais em confronto na sociedade em que vive. Em outras palavras, não existe produção descompromissada dos interesses sociais e seus respectivos projetos que se colocam em conflito na arena social ou ainda, o conhecimento produzido é socialmente condicionado pelas condições materiais existentes e pelos interesses de classe.

Nesse sentido, as "novas abordagens" sobre a História procuram subtrair-lhe a dimensão do conflito, homogeneizando as relações sociais, em esforço evidente para omitir a exploração e a dominação no passado, de forma a naturalizar a exploração e a dominação de hoje. Não por acaso, o desencanto com o "progresso" e a crise dos paradigmas da racionalidade gerou posturas que procuraram demonstrar a "impossibilidade" de se conhecer o passado.

Por esta razão, reafirmamos a necessidade de continuar pesquisando os arquivos que possam contribuir para a produção historiográfica sobre a História da Educação Brasileira. Explicar o passado, prenhe dos acontecimentos humanos, em função do presente, talvez seja essa a principal função social da história. Mediante suas fontes, o desafio do historiador consiste a rigor dar significado as atitudes, valores, intenções e convenções que fazem parte das ações humanas. $\mathrm{O}$ desafio do trabalho do historiador da educação consistirá num esforço constante fazer suas fontes falarem sobre os homens, sobre a sociedade que as produziu. A rigor, cada um de nós, como historiador da educação, para além de não esquecer, temos que explicar o passado, por mais que seja dolorido.

Questionar as estruturas do poder de uma sociedade, setores que orientavam para onde a história devia caminhar, ou seja, o poder sobre a memória futura, tudo deve ser e desmontado pelo 
historiador. Como sabemos, não existe documento inocente, cabendo ao historiador a capacidade de discernir o que é "falso", e o que é "verdadeiro" desmistificando e verificando sua credibilidade.

Visitar as fontes tem sentido na medida em que visa destruir no cotidiano a pseudoconcreticidade, desvendando a essência de sua aparência. Para, além disso, o contato, a análise e a crítica das fontes e o exame dos arquivos significa uma crítica da civilização e da cultura. O estudo do cotidiano ou da totalidade deve desvendar por trás de sua aparente neutralidade, a autêntica realidade do homem concreto. $\mathrm{O}$ estudo do cotidiano desvinculado da história é uma mistificação, da mesma forma que estudar a totalidade ausente de um rigor dialético fica reduzido a uma especulação vazia, sem sentido. A investigação do fenômeno deve realizar a passagem do pensamento mítico (o aparente) para o pensamento dialético (a essência). O esforço filosófico, desvalorizado pelas abordagens pós-modernas, consiste neste desafio. Muitos acontecimentos deflagram verdadeira batalha pelo controle da memória.

O combate a amnésia deve ser uma tarefa sempre presente no trabalho do historiador da educação. Face ao exposto o confronto entre história e memória e história da educação revela um potencial de novas possibilidades de pesquisas a ser explorado. O desafio do trabalho do historiador da educação consistirá num esforço constante fazer suas fontes falarem sobre os homens, sobre a sociedade que as produziu. Como nos alerta Bosi (1997), a memória não é sonho, é trabalho.

\section{Referências}

ARÓSTEGUI, Julio. A pesquisa histórica: teoria e método. Bauru: Ed.USC, 2006.

BENJAMIN, Walter. O narrador: considerações sobre a obra de Nicolai Leskov. In: Magia

e Técnica, Arte e Política. Obras Escolhidas I. São Paulo: Brasiliense, 1994b. p.197-221.

BLOCH, Marc. Introdução à História. 2. ed. Lisboa, PT: Europa América, 1974.

BLOCH, Marc. Apologia a história, ou o oficio do historiador. Rio de Janeiro: Zahar, 2001.

BOSI, Ecléa. Memória e sociedade: lembranças de velhos. São Paulo: T.A. Queiroz, 1979.

BURKE, Peter. A escrita da história. Lisboa, PT: Difel, 1992.

LE GOFF, Jacques. História e Memória. Campinas, SP: Ed. UNICAMP, 1994.

LOPES, Eliana Marta; GALVÃO, Ana Maria de Oliveira. História da educação. Rio de Janeiro: DP\&A, 2001.

LOMBARDI, José Claudinei; NASCIMENTO, Maria Isabel Moura de (Org.). Fontes, história e historiografia da educação. Campinas, SP: Autores Associados: HISTEDBR; Curitiba, PR: Pontifícia Universidade Católica do Paraná (PUCPR); Palmas, PR: Centro Universitário Diocesano do Sudoeste do Paraná (UNICS); Ponta Grossa, PR; Universidade Estadual de Ponta Grossa (UEPG), 2004. 
PENN, Lincoln de Abreu. História, uma História: memória e conhecimento. Rio de Janeiro: E. Papers, 2009.

SCHAFF, Adam. História e Verdade. Tradução Maria Paula Duarte. São Paulo, Martins Fontes, 1995.

Recebido em: 26/11/2015

Aceito em: 05/08/2016 